\title{
Cloning and functional characterization of early B-cell factor, a regulator of lymphocyte-specific gene expression
}

\author{
James Hagman, Carole Belanger, Adam Travis, Christoph W. Turck, ${ }^{1}$ and Rudolf Grosschedl \\ Howard Hughes Medical Institute and Departments of Microbiology and Biochemistry; ${ }^{1}$ Protein Structure Laboratory \\ and Department of Medicine, University of California, San Francisco, California 94143 USA.
}

\begin{abstract}
Early B-cell factor (EBF) was identified previously as a tissue-specific and differentiation stage-specific DNA-binding protein that participates in the regulation of the pre-B and B lymphocyte-specific $m b-1$ gene. Partial amino acid sequences obtained from purified EBF were used to isolate cDNA clones, which by multiple criteria encode EBF. The recombinant polypeptide formed sequence-specific complexes with the EBF-binding site in the $m b-1$ promoter. The cDNA hybridized to multiple transcripts in pre-B and B-cell lines, but transcripts were not detected at significant levels in plasmacytoma, T-cell, and nonlymphoid cell lines. Expression of recombinant EBF in transfected nonlymphoid cells strongly activated transcription from reporter plasmids containing functional EBF-binding sites. Analysis of DNA binding by deletion mutants of EBF identified an amino-terminal cysteine-rich DNA-binding domain lacking obvious sequence similarity to known transcription factors. DNA-binding assays with cotranslated wild-type and truncated forms of EBF indicated that the protein interacts with its site as a homodimer. Deletions delineated a carboxy-terminal dimerization region containing two repeats of 15 amino acids that show similarity with the dimerization domains of basic-helix-loop-helix proteins. Together, these data suggest that EBF represents a novel regulator of B lymphocyte-specific gene expression.
\end{abstract}

[Key Words: EBF; $m b-1$ gene expression; transcription factor; B-cell differentiation]

Received February 5, 1993; accepted February 26, 1993.

Cell type-specific DNA-binding proteins are instrumental for the selective transcription of eukaryotic genes in diverse cell types. These proteins, together with ubiquitous factors, generate the specific pattern of gene expression that is characteristic for a particular cell type (for review, see Herskowitz 1989). Moreover, the pattern of gene expression is temporally regulated during the differentiation of progenitor cells into highly specialized cells.

The differentiation of B lymphocytes from committed precursor cells to antibody-secreting plasma cells includes at least four stages that can be distinguished by changes in the expression of genes encoding the immunoglobulin heavy chains, light chains, and accessory proteins (for review, see Rolink and Melchers 1991). Pro-B cells have immunoglobulin genes in an unrearranged and transcriptionally inactive state. Pre-B cells are characterized by the rearrangement and expression of the $\mu$ heavychain locus. The subsequent rearrangement and expression of immunoglobulin light-chain loci result in the synthesis of membrane-bound heteromeric IgM complexes $\{\mathrm{mIgM} \mid$ that are displayed on the surface of immature B cells. Together, these stages have been defined as the early, antigen-independent phase of B-cell differentiation. Following the stimulation of $\mathrm{mIg}^{+} \mathrm{B}$ cells by an- tigen, these cells differentiate into antibody-secreting plasma cells representing the terminal stage of the B-cell lineage.

Although much is known concerning the regulation of immunoglobulin genes, very little is understood about the regulation of genes that express mIg-associated molecules in the early stages of B-cell differentiation. In particular, the question arises as to whether additional or distinct nuclear factors are involved in the regulation of these genes. As an example of such a gene, mb-1 transcripts have been detected in cell lines that are representative of the early stages of B-cell differentiation, including pre-B and $\mathrm{mIgM}^{+} \mathrm{B}$-cell lines but not in cell lines representing plasma cells, $\mathrm{T}$ cells, and nonlymphoid cells (Sakaguchi et al. 1988). The $m b$-1-encoded protein $(\operatorname{Ig} \alpha)$, together with the product of the B29 gene $(\operatorname{Ig} \beta)$, associates with IgM /Campbell and Cambier 1990; Hombach et al. 1990) or the other immunoglobulin classes on the B-cell surface (Venkitaraman et al. 1991) and participates in signal transduction (Matsuuchi et al. 1992). In plasmacytomas representing terminally differentiated plasma cells, the synthesis of $\operatorname{IgM}$ is switched from the membrane-bound form to the secreted form and the $m b-1$ gene is shut off (Sakaguchi et al. 1988).

Previous analysis of the $m b-1$ promoter indicated that 
a 325-bp DNA fragment directs lineage- and stage-specific transcription from multiple start sites in transfection assays (Travis et al. 1991b). Deletions and linkerscanning mutations revealed two functionally important sets of elements upstream of the major transcription initiation sites. The elements most proximal to the initiation sites were found to be essential for promoter function. Our studies with these proximal promoter elements, however, did not identify any DNA-binding activities with the same cell-type distribution as $m b-1$ transcripts (Travis et al. 1991b; Hagman and Grosschedl 1992). Characterization of the distal $m b-1$ promoter region identified a sequence element that was protected from DNase I cleavage by a nuclear factor present in pre-B and $\mathrm{mIg}^{+} \mathrm{B}$-cell lines but not present in fibroblast, plasmacytoma, or T cell lines (Hagman et al. 1991). This early B-cell-specific DNA-binding protein was termed early B-cell factor (EBF). A factor with many of the properties of EBF was described independently as B-Lyf (Feldhaus et al. 1992). The DNA-binding specificity of EBF was found to be distinct from that of other temporally regulated DNA-binding proteins of the B-cell lineage, including Oct-2 (for review, see Staudt and Lenardo 1991), NFkB (for review, see Lenardo and Baltimore 1989), and B-cell-specific activator protein (BSAP) (Adams et al. 1992; Kozmik et al. 1992). The functional importance of the EBF-binding site was demonstrated by two assays. First, mutation of the EBF-binding site decreased $m b-1$ promoter activity fourfold in short-term transfection assays in pre-B cells (Hagman et al. 1991). Second, the EBFbinding site, either in the context of flanking sequences or by itself, conferred activation on a heterologous promoter in pre-B cells but not in cells that do not contain EBF (Hagman et al. 1991; Feldhaus et al. 1992). Together, these data described EBF as a novel factor involved in early B-cell-specific gene expression.

Recently, we purified EBF by sequence-specific DNA affinity chromatography and characterized it biochemically (Travis et al. 1993). We found that polypeptides in the range of $62-65 \mathrm{kD}(\mathrm{p} 62-65)$ could be fractionated by SDS-PAGE, eluted from the gel, and renatured to reconstitute a sequence-specific DNA-binding activity indis- tinguishable from EBF. Estimates of the size of native EBF by use of gel filtration chromatography indicated a radius of gyration for a globular protein of $140 \mathrm{kD}$, suggesting that EBF exists as a dimer of $62-65 \mathrm{kD}$ subunits (Travis et al. 1993).

In this report we describe the cloning of cDNAs encoding a polypeptide, which, by all criteria examined, represents EBF. The recombinant protein contains two independent domains that are required for DNA binding and homodimerization. Moreover, EBF is a potent activator of gene expression, suggesting that the protein has a regulatory role in B lymphocytes and, possibly, other cell types.

\section{Results}

Isolation of cDNAs encoding p64/EBF

EBF was purified from crude nuclear extracts of the murine pre-B-cell line $38 \mathrm{~B} 9$ by a combination of cation exchange and oligonucleotide affinity chromatography (Kadonaga and Tjian 1986) and further fractionated by SDSPAGE. Polypeptides of $62-65 \mathrm{kD}$ were isolated and cleaved with trypsin. Peptides were separated by reversephase HPLC for amino-terminal sequencing. Four peptides yielded the amino acid sequences shown in Table 1. The sequences of peptides RA39 and RA61 were used to design four degenerate oligonucleotide primers corresponding to the predicted sense and antisense nucleotide sequences of a portion of each peptide. One pair of primers allowed for the amplification of a 707-bp DNA fragment from a murine pre-B cell (38B9) cDNA library (Rudin et al. 1990) by use of the polymerase chain reaction (PCR).

Comparison of the nucleotide sequence of the amplified PCR fragment with the combined PIR, GENPEPT, and SWISSPROT data bases indicated that we had cloned a previously unreported cDNA sequence. The identity of the PCR fragment as part of the sequence of the purified polypeptides was confirmed by a match between the nucleotide sequence adjacent to the primers and the codons predicted for the amino acid sequence of peptide RA61

Table 1. Amino acid sequence of tryptic peptide fragments of p62-65

\begin{tabular}{|c|c|c|c|c|}
\hline Peptide & Position $^{a}$ & Residues $^{\mathrm{b}}$ & Amino acid sequence ${ }^{c}$ & Probes $^{\mathrm{d}}$ \\
\hline RA39 & $122-129$ & 8 & TEQDFYVR & ACNGARCARGAYTTYTAYGT \\
\hline RA51 & $87-99$ & 13 & (F) A ( L ) VGFVEKEKEA & \\
\hline RA55 & $382-390$ & 9 & AADLVEALY & \\
\hline RA61 & $342-358$ & 17 & FI YTALNE PTIDYGFQR & TGR AANCCRTARTC $\mid$ A / G / T $\mid$ ATNGT \\
\hline
\end{tabular}

Preparation and analysis of peptides is described in Materials and methods.

${ }^{a}$ Coordinates of each peptide relative to the putative initiator methionine in the predicted amino acid sequence of EBF in $\phi E B F 17$. ${ }^{b}$ Number of amino acids in each peptide.

${ }^{\mathrm{c}}$ Amino acids in parentheses deviate from the predicted amino acids in recombinant EBF at positions $87(\mathrm{~T})$ and $89(\mathrm{~F})$. Underlined amino acids were used for the design of degenerate oligonucleotide probes.

${ }^{\mathrm{d}}$ Nucleotide sequences of the degenerate oligonucleotides used for PCR amplification. Degenerate nucleotides encode underlined amino acids in fourth column. 
(see Table 1). Because the cDNA sequence was too short to encode a $62-$ to $65-\mathrm{kD}$ polypeptide, we used the PCR fragment to probe a $\lambda$ gt $11 \mathrm{cDNA}$ library of the murine pre-B-cell line 70Z/3 (Ben-Nariah et al. 1986). The PCR fragment hybridized to three independent phage clones from a pool of 400,000 , and restriction site mapping indicated that the clones contain overlapping sequences.
The nucleotide sequence was determined for both strands of the longest phage insert ( $\phi E B F 17$; Fig. 1).

The nucleotide sequence of the $\phi \mathrm{EBF} 17$ insert suggests an open reading frame (ORF) from nucleotides 46-1818. Conceptual translation of the nucleotide sequence from the first ATG codon yields a polypeptide of 591 amino acids with a molecular mass of $64.4 \mathrm{kD}$ (p64), which is in

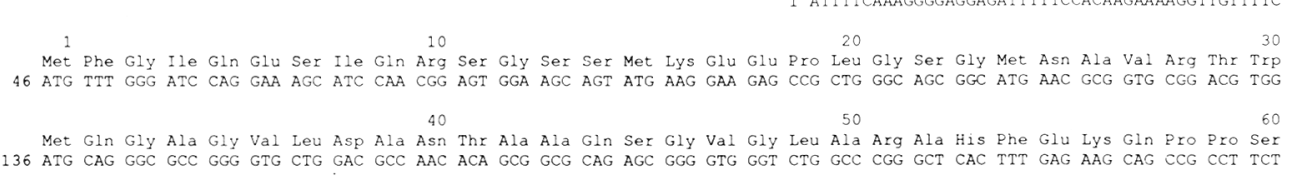
70
Asn Leu Arg Lys Ser Asn Phe Phe His phe Val Leu Ala leu Tyr Asp Arg Gin Gly Gin Pro Val Glu Ile Glu Arg Thr Ala phe Val
226 AAC CTG CGG ARA TCC AAC TTC TTC CAC TTC GTC CTG GCC CTC TAC GAC AGA CAG GGC CAG CCC GTG GAG ATT GAG AGG ACT GCC TTT GTG

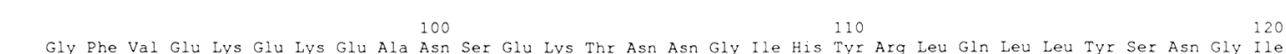
Gly phe Val Glu lys Glu lys Glu Ala Asn Ser Glu Lys Thr Asn Asn Gly ile His Tyr Arg leu Gin Leu leu Tyr Ser Asn Gly Ile
316 GGG TTC GTG GAG AAG GAA AAA GAA GCC AAC AGC GAA AAG ACC AAT AAT GGG ATC CAC TAC CGG CTC CAG CTC CTC TAC AGC AAT GGG ATA Arg Thr Glu Gln Asp phe Tyr Val Arg Leu Ile Asp Ser Met Thr Lys Gln Ala Ile Val Tyr Glu Gly Gln Asp Lys Asn Pro Glu Met Arg Thr Glu Gln Asp phe Tyr Val Arg leu Ile Asp Ser Met Thr Lys Gln Ala Ile Val Tyx Glu Gly Gln Asp lys Asn Pro Glu Met
406 CGG ACA GAA CAG GAT tTC TAT GTG CGC CTC ATC GAC TCC ATG ACA AAA CAA GCC ATA GTG TAT GAA GGC CAA GAC AAG AAC CCT GAA ATG Cys Arg Val Leu Leu Thr His Glu Ile Met Cys Ser Arg Cys Cys Asp Lys Lys Ser Cys Gly Asn Arg Asn Glu Thr Pro Ser Asp Pro
496 TGC CGA GTA TTG CTC ACA CAC GAG ATC ATG TGC AGC CGC TGT TGT GAC AAG AAA AGC TGT GGC AAC CGA AAT GAG ACT CCC TCA GAT CCA

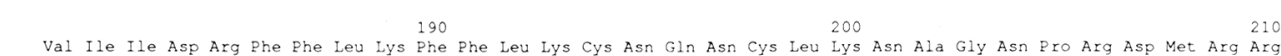
Val Ile Ile Asp Arg phe phe Leu Lys phe phe Leu Lys Cys Asn Gin Asn Cys leu Lys Asn Ala Gly Asn Pro Arg Asp Met Arg Arg
586 GTG ATA ATT GAC AGG TTC TTC CTG AAG TTT TTC CTT AAA TGC AAC CAA AAT TGC CTA AAG AAT GCA GGA AAC CCA CGT GAC ATG CGG AGA 220
Phe Gin Val Val Val Ser The Thr Val Asn Val Asp Gly His Val Leu Ala Val Ser Asp Asn Met Phe Val His Asn Asn Sex Lys His
240
676 TTC CAG GTC GTG GTG TCT ACC ACA GTC AAC GTG GAT GGC CAT GTC CTG GCA GTC TCT GAT AAC ATG TTT GTC CAC AAT AAC TCC AAG CAC Gly Arg Arg Ala Arg Arg Leu Asp Pro Ser Glu Gly Thr Pro Ser Tyr Leu Glu His Ala Thr pro Cys Ile Lys Ala Ile Ser pro Ser
766 GGG CGG AGG GCT CGG AGG CTT GAC CCC TCG GAA GGT ACG CCC TCT TAT CTG GAA CAT GCT ACT CCC TGT ATC AAA GCC ATC AGC CCG AGT $280 \quad 290 \quad 300$ Glu Gly Trp Thr Thr Gly Gly Ala Thr Val Ile Ile Ile Gly Asp Asn phe Phe Asp Gly Leu Gin val Ile phe Gly Thr Met Leu Val
856 GAA GGA TGG ACG ACG GGA GGC GCG ACT GTG ATC ATC ATA GGG GAC AAT TTC TTT GAT GGG TTA CAG GTC ATA TTC GGT ACC ATG CTG GTC 31003200 Trp Ser Glu Leu Ile Thr Pro His Ala Ile Arg Val Gln Thr Pro fro Arg His Ile Pro Gly Val Val glu val Thr Leu Ser Tyr Lys
946 TGG AGT GAG TTG ATA ACT CCT CAT GCC ATC CGA GTT CAG ACA CCT CCT CGG CAC ATC CCr GGT GTG GTG GAA GTC ACA CTG TCG TAC AAG

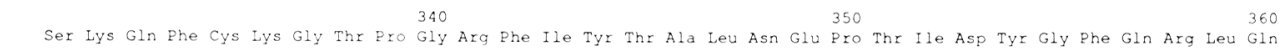
Ser Lys Gin phe Cys Lys Gly Thr Pro Gly Arg Phe Ile Tyr Thr Ala leu Asn Glu pro Thr Ile Asp Tyr Gly phe Gin Arg leu Gin
1036 TCC AAG CAG TTC TGC AAA GGG ACA CCA GGC AGA TTC ATC TAC ACA GCA CTC AAT GAA CCC ACC ATC GAC TAC GGC TTC CAG AGG TTA CAG

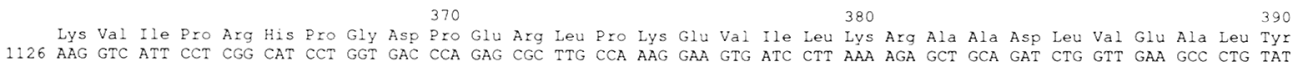
Gly Met Pro His Asn Asn Gln Glu Ile Ile Leu Lys Arg Ala Ala 410 Gly Met Pro His Asn Asn Gin Glu Ile Ile Leu Lys Arg Ala Ala Asp ile Ala Glu Ala leu Tyr Ser val pro Arg Asn His Asn Gin
216 GGG ATG CCC CAC AAC AAC CAG GAG ATT ATC CTG AAG AGA GCT GCC GAC ATT GCA GAG GCT CTG TAC AGT GTC CCT CGG AAC CAC AAC CAG

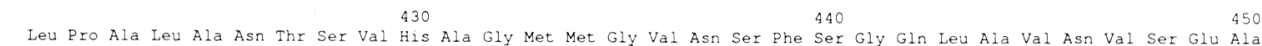
Leu Pro Ala leu Ala Asn Thr Ser Val His Ala Gly Met Met Gly Val Asn Ser Phe Ser Gly Gin Leu Ala Val Asn Val Ser Glu Ala
1306 CTC CCA GCC CTT GCT AAC ACT TCG GTC CAT GCA GGG ATG ATG GGT GTG AAC TCC TTC AGT GGA CAA CTG GCT GTG AAT GTC TCG GAG GCA Ser Gin Ala Thr Asn Gin Gly Phe Thr Arg Asn Ser Ser Ser Val Ser Pro His Giy Tyr Val pro Ser Thr Thr Pro Gin Gin Thr Asn
1396 TCA CAA GCC ACC AAT CAA GGT TTC ACC CGC AAC TCA AGC AGC GTG TCA CCA CAT GGC TAT GTG CCG AGC ACC ACC CCA CAG CAA ACC AAC Tyr Asn Ser Val The Thr Ser Met Asn Gly Tyr Gly Ser Ala Ala Met Ser Asn leu Gly Gly Ser Pro Thr phe Leu Asn Gly Ser Ala
1486 TAT AAC TCA GTC ACC ACA AGC ATG AAT GGC TAC GGC TCA GCC GCC ATG TCC AAT TTG GGC GGC TCC CCA ACC TTC CTC AAT GGC TCA GCT Ala Asn Ser Pro Tyr Ala Ile Val pro Ser Ser Pro Thr Met Ala Ser Ser Thr Ser Leu Pro Ser Asn Cys Ser Ser Ser Ser Gly 540 Ala Asn Ser Pro Tyr Ala Ile Val pro Ser Ser Pro The Met Ala Ser Ser Thr Ser Leu Pro Ser Asn Cys Ser Ser Ser Ser Gly Ile
1576 GCC AAC TCA CCC TAT GCC ATT GTG CCA TCC AGC CCC ACC ATG GCC TCA TCT ACA AGC CTC CCC TCC AAC TGC AGT AGC TCC TCT GGC ATC Phe Ser phe Ser Pro Ala Asn Met Val Ser Ala val lys Gin Lys Ser Ala phe Ala Pro Val val Arg pro Gin Thr Ser Pro Pro Pro
1666 TTC TCC TTC TCA CCA GCC AAC ATG GTC TCA GCA GTG AAA CAG AAG AGT GCT TTC GCA CCA GT: GTC AGA CCC CAG ACG TCC CCT CCT CCC Thr Cys Thr Ser Thr Asn Gly Asn Ser Leu G1n Ala Ile Ser Gly Met Ile Val Pro Pro Met OP
1756 ACC TGC ACC AGC ACC AAC GGG AAC AGC CTG CAA GCG ATA

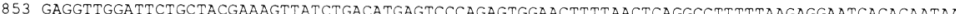

1972 TGCAA.ATACTGAAATTGGAAAGGGGGTCTGCCAGAGCAGGGTGTTGGTTAAAGTTGTAACCCCCGAGTATCTGGGGGATATATTTATTCTGTATT GATAAAAAGCAAGCCCACATTTTC

2091 TTTrTCTTTCTTTCTTT TCTTAAGCTTAACTCTGCAACCATTTGTCTTTTATAAACCATTAAGCTACACACAAGGGCCACTATAAACAAGACTCCATGTTTTAATTTATGTTTTTAAAG

Figure 1. Nucleotide sequence of the cDNA insert of $\phi \mathrm{EBF} 17$ and predicted amino acid sequence of the encoded polypeptide. The nucleotide sequence of the insert of $\phi \mathrm{EBF} 17$ is shown together with the translated sequence of the longest ORF. The nucleotide sequence is numbered at left. Amino ącids are numbered above each line. 
close agreement with our estimates for EBF polypeptides purified from nuclear extract (Travis et al. 1993). The first ATG codon in the longest ORF is not preceded by an in-frame termination codon in the cDNA insert. The PCR amplification of a cDNA sequence upstream from the $5^{\prime}$ end of $\phi E B F 17$, however, indicates the presence of an in-frame termination codon (data not shown). Therefore, together with the close agreement between the calculated mass of the translated ORF (p64) and the experimentally determined molecular mass of purified EBF polypeptides (p62-65), the $\phi E B F 17$ insert appears to contain the entire ORF. This ORF also contains the amino acid sequences of the two other tryptic peptides obtained from purified p62-65, which were not used to design primers for the amplification reaction. Comparison of the amino acid sequence of p64 with the current data bases revealed only one homology with known proteins: Two repeats of 15 amino acids were found to be related in sequence to members of the basic-helix-loop-helix (bHLH) family of DNA-binding proteins (see below).

\section{Sequence-specific DNA binding by recombinant EBF}

To confirm that the cDNA clones encode EBF, we compared specific DNA binding by p64 with EBF from nuclear extracts. Recombinant p64 protein was synthesized from the $\phi E B F 17$ insert by in vitro transcription and translation. The protein products were examined for specific DNA binding to a labeled $m b-1$ promoter probe in an electrophoretic mobility retardation assay. The relative migrations of the major, and some minor, proteinDNA complexes formed with recombinant p64 were identical with those of complexes formed with pre-B cell nuclear extracts (Fig. 2, cf. lanes 11-19 with 2-10). Moreover, all shifted complexes were competed by an unlabeled duplex oligonucleotide containing the wild-type EBF-binding site (Fig. 2, lanes 3-6 and 12-15), and not by a mutant oligonucleotide containing a single $\mathrm{C} \rightarrow \mathrm{A}$ substitution in the EBF site (Fig. 2, lanes 7-10 and 16-19). This mutation was shown previously to drastically reduce DNA binding by EBF (Hagman et al. 1991).

The contacts made by recombinant $\mathrm{p} 64$ with the $m b-1$ distal promoter region were analyzed using a methylation interference assay (Fig. 3). DNA binding by recombinant p 64 was decreased by methylation of virtually the same set of nucleotides that interfered with the binding of EBF in crude nuclear extracts (Hagman et al. 1991). Together, these data suggest that p64 represents EBF.

\section{Expression of EBF mRNA in cell lines and adult mouse tissues}

To examine the cell-type and tissue distribution of EBF transcripts, we hybridized an RNA blot containing poly $\langle\mathrm{A}\}^{+}$-selected mRNA from various lymphoid and nonlymphoid cell lines with a labeled EBF cDNA probe (Fig. 4A, upper panel). To control for RNA quantity and transfer, the RNA blot was reprobed with a labeled $\beta$-actin-specific DNA probe (lower panel). Five distinct mRNAs of $5.8,5.2,4.6,3.8$, and $2.7 \mathrm{~kb}$ were detected in

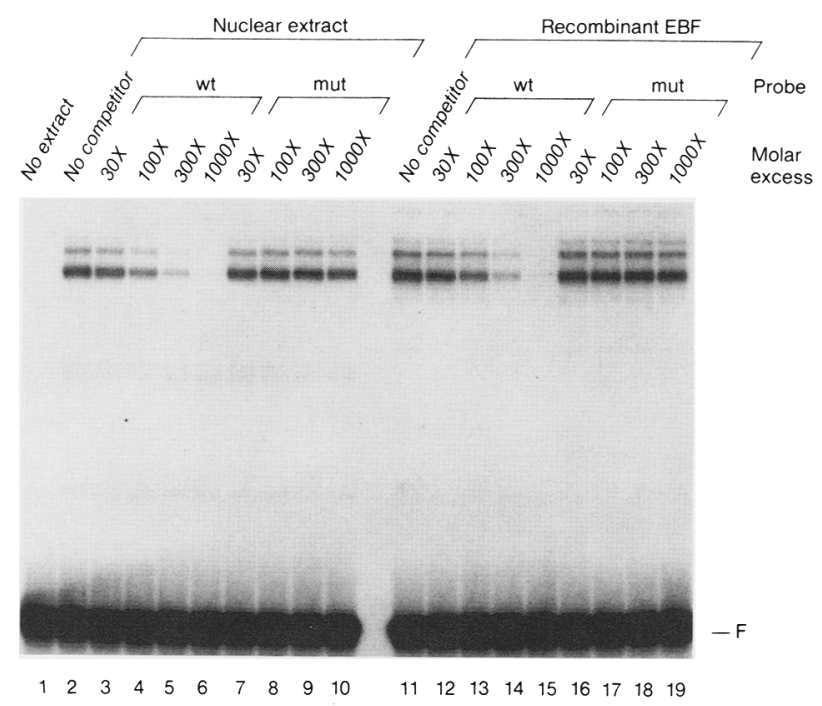

Figure 2. The DNA-binding specificity of recombinant p64 is identical with that of EBF in nuclear extracts. Electrophoretic mobility retardation assay with a ${ }^{32}$ P-labeled double-stranded oligonucleotide probe comprising nucleotides -183 to -154 of the $m b-1$ promoter (Hagman et al. 1991). The labeled DNA probe was incubated with $100 \mathrm{ng}$ of unfractionated pre-B cell (PD36) nuclear extract (left), or $2 \mu$ l reticulocyte lysate translation programmed with RNA transcribed from the $\phi E B F 17$ insert sequence (recombinant EBF, right). Protein-DNA complexes were separated from free DNA probe $\{F\rangle$ by electrophoresis through a nondenaturing polyacrylamide gel. For competition with protein binding, increasing amounts of unlabeled competitor oligonucleotides were included in the reaction as indicated. The double-stranded competitor oligonucleotides contained the wild-type (wt) $m b-1$ promoter sequence $(-183$ to -154$)$ or a mutated (mut) sequence containing a $\mathrm{C} \rightarrow$ A point mutation at nucleotide -173 (Hagman et al. 1991).

all murine pre-B and $\mathrm{mIg}^{+} \mathrm{B}$-cell lines (lanes $1-5$ and 6-7). These signals were absent in three of five plasmacytoma cell lines (lanes 9,10,12), all T cell lines (lanes 13-15), and all but one nonlymphoid cell line (lanes 1618). Weak hybridization was detected with mRNA from the plasmacytoma lines SP2 and MPC11 (lanes 8,11) and also from NIH-3T3 fibroblasts (lane 19) at a level 20- to 100 -fold lower than found in early B cells. A high level of specific EBF mRNA was detected in a human $B$ lymphoblastoid cell line (BJA-B; data not shown), indicating a high degree of sequence conservation between EBF transcripts of mice and humans. This analysis suggested that high levels of EBF expression are restricted to early stage-B cells, paralleling the distribution of EBF DNAbinding activity (Hagman et al. 1991).

The distribution of EBF mRNAs in adult murine tissues was examined by use of an S1 nuclease protection assay with a labeled EBF cDNA fragment (Fig. 5). The probe was protected by transcripts in spleen, lymph node, and adipose tissues at a high level (lanes 1,2,13), and in several nonlymphoid tissues at a low level. The DNA probe was specific for EBF transcripts, because it was protected by mRNA sequences present in early 


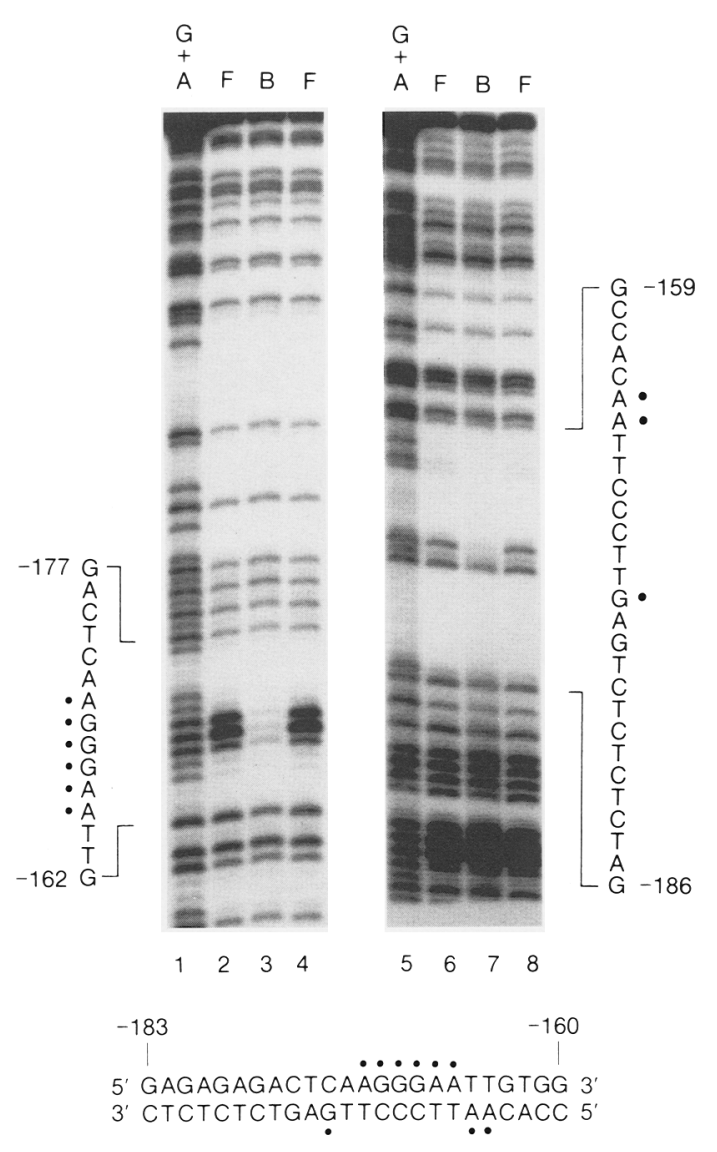

Figure 3. Methylation interference analysis of DNA binding by recombinant EBF. The coding (lanes $1-4$ ) and noncoding (lanes 5-8) strands of the $m b-1$ promoter probes (comprising nucleotides -243 to -126 or -252 to -113 , respectively) were $3^{\prime}$-end-labeled with ${ }^{32} \mathrm{P}$ and partially methylated with dimethylsulfate. Probes were incubated with rabbit reticulocyte lysate programmed with RNA transcribed from the cDNA insert of $\phi E B F 17$. Bound $(B)$ and free $(F)$ probes were separated on a nondenaturing polyacrylamide gel and processed as described previously (Hagman et al. 1991). Reference $\mathrm{G}+\mathrm{A}$ cleavage reactions (Sambrook et al. 1989) are shown in lanes 1 and 4 . (O) Methylated bases that interfere with DNA binding by recombinant EBF. N3-adenosine methylation interference can be seen weakly. A summary of the interference pattern is shown below.

B-cell lines (data not shown) but not by mRNA isolated from a T-cell line (EL4) or nonlymphoid cell lines (HeLa and $\operatorname{Cos} 7)$. As a control for the presence of B lymphocytes in tissue samples, we also analyzed the RNA samples with an Igк-specific probe (Jenuwein and Grosschedl 1991). As expected, spleen and lymph nodes, which contain high proportions of $B$ cells, express high levels of $\kappa$ transcripts (Fig. 5A, lanes 1,2). Low levels of $\kappa$ transcripts, however, were also observed in thymus, lung, and salivary gland (lanes $3,7,10$ ), suggesting that the EBF transcripts observed in these tissues were probably attributable to contaminating B lymphocytes. The absence of detectable $\kappa$ transcripts in other nonlymphoid tissues indicated that EBF is expressed at low levels in heart, brain, skeletal muscle, and kidney (lanes $4,5,6,9)$. To- gether, the data indicate that EBF is expressed predominately in lymphoid and adipose tissues and is restricted within the lymphoid compartment to the early stages of the B-cell lineage.

\section{Activation of transcription by $E B F$}

We and others have shown previously that the EBF-binding site can augment transcription from heterologous promoter/reporter plasmids in transfected early B cell lines but not in cell lines that lack EBF (Hagman et al. 1991; Feldhaus et al. 1992). To confirm that EBF is an activator of transcription, we transfected reporter plasmids together with an effector plasmid allowing for expression of full-length EBF, into HeLa cells. The reporter plasmids contained either one copy of the 105-bp mb-1 distal promoter fragment (Hagman et al. 1991) or two copies of a 30-bp synthetic oligonucleotide comprising an EBF-binding site, inserted just upstream of the minimal $\beta$-globin promoter in OVECS (Westin et al. 1987;

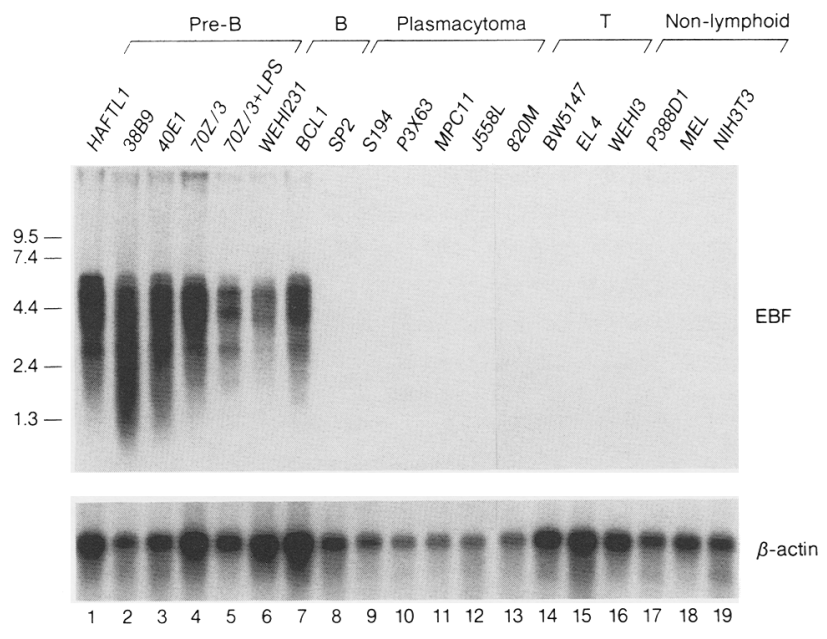

Figure 4. RNA blot analysis of the distribution of EBF transcripts in hematopoietic cell lines. Poly $(\mathrm{A})^{+}$-selected cytoplasmic RNA $(5 \mu \mathrm{g})$ from various tissue culture cell lines was size fractionated by gel electrophoresis, transfered to a nylon membrane, and hybridized (top) with a ${ }^{32} \mathrm{P}$-labeled DNA probe derived from the $\$ \mathrm{EBF} 17$ cDNA (SmaI-AvaII, nucleotides 1971332). Lymphoid cell lines include fetal liver-derived pre-B cells (HAFTL1, 38B9, and 40E1), an adult bone marrow-derived pre-B cell (70Z/3), $\mathrm{mIg}^{+} \mathrm{B}$-cell lymphomas (WEHI231 and BCL1), plasmacytomas (SP2, S194, P3X63, MPC11, and J558L), and T cell tumors (820M, BW5147, and EL4). Nonlymphoid cells include myeloid cells (WEHI3 and P388D1), erythroleukemia cells (MEL), and fibroblasts (NIH-3T3). (Lane 5) 70Z/3 Pre-B lymphoma cells were treated for $24 \mathrm{hr}$ with bacterial lipopolysaccharide, which can increase the levels of the transcription factors NFKB (Sen and Baltimore 1986) and Oct-2 (Staudt et al. 1988 ) in $70 Z / 3$ cells. The sizes of the major EBF transcripts were determined as $5.8,5.2,4.6,3.8$, and $2.7 \mathrm{~kb}$ by comparison with RNA molecular mass markers (BRL) electrophoresed in parallel and detected by rehybridization with ${ }^{32} \mathrm{P}$-labeled bacteriophage $\lambda$ DNA (not shown). To control for RNA levels, the RNA blots were stripped and rehybridized with a ${ }^{32}$ p-labeled murine $\beta$-actin probe (bottom). 


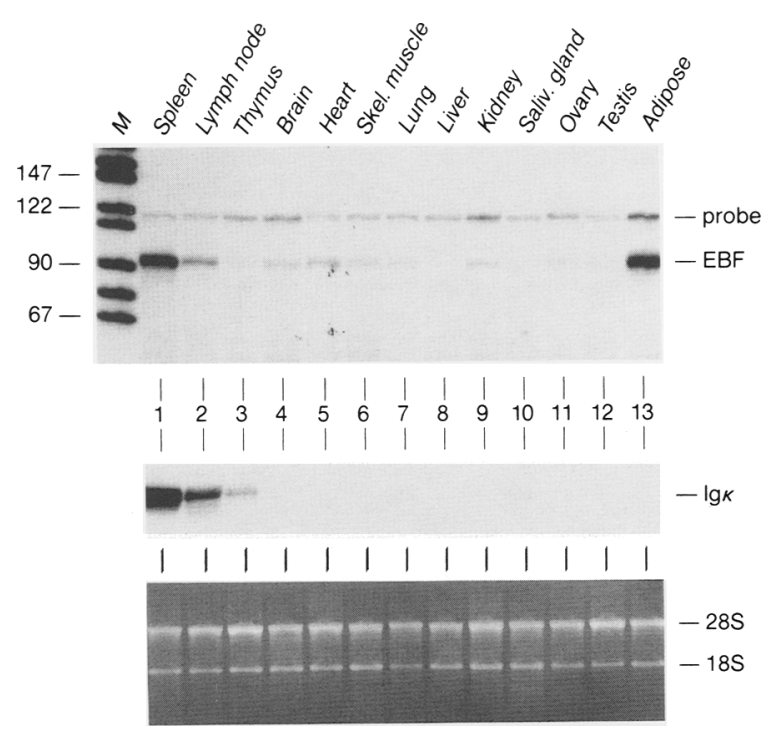

Figure 5. Sl nuclease protection analysis of EBF transcripts in mouse tissue mRNAs. Total RNA $(20 \mu \mathrm{g})$ from various tissues was hybridized with a $5^{\prime}$-end-labeled single-stranded EBF DNA probe, digested with Sl nuclease, and fractionated by gel electrophoresis (top). The EBF-specific probe contained 89 nucleotides of the EBF cDNA sequences (nucleotides $365-454$ ) and 31 nucleotides of the Bluescript KS + polylinker at the $3^{\prime}$ end (see Materials and methods). Residual undigested probe (probe) and the fragment protected by EBF transcripts (EBF) are indicated. To detect contamination of tissues with B lymphocytes (middle), an Igк constant region-specific probe was used for S1 nuclease analysis in parallel (Jenuwein and Grosschedl 1991). To control for RNA levels (bottom), $2 \mu \mathrm{g}$ of each RNA sample was stained with ethidium bromide and electrophoresed as described (Fourney et al. 1988).

Feldhaus et al. 1992). In a parallel experiment, we transfected the reporter plasmids with an effector plasmid that transcribes the EBF-coding sequence in the antisense orientation. Each transfection also included the OVEC-RF reference plasmid to control for transfection efficiency and RNA recovery. At $48 \mathrm{hr}$ post-transfection, total cellular RNA was isolated and analyzed by $\mathrm{S} 1 \mathrm{nu}-$ clease protection with a labeled $\beta$-globin single-stranded DNA probe specific for both the OVECS test and reference transcripts (Fig. 6B). The EBF effector plasmid activated transcription 30-fold from reporter plasmids containing either the 105- or 30-bp $\mathrm{mb}$-1 promoter segments (Fig. 6A). No significant activation by wild-type EBF was observed with either the OVECS reporter plasmids containing a mutant EBF-binding site or the unmodified OVECS plasmid. Moreover, activation was dependent on the expression of EBF, because no activation was observed when the effector plasmid contained the EBF cDNA in the antisense orientation. Thus, EBF is a strong activator of gene expression.

\section{Separate domains contribute to DNA binding and dimerization}

Alignment of the amino acid sequence of EBF with the sequences of other proteins using the BLASTP 1.2 .5 algorithm (Altschul et al. 1990) did not reveal any extended homology to known DNA-binding domains. To determine the regions of EBF that are involved in specific DNA binding, we generated amino- and carboxy-terminal truncated forms of the protein by in vitro transcription and translation of mutated EBF cDNAs (Fig. 7A). For each deletion mutation, the efficiency of translation was

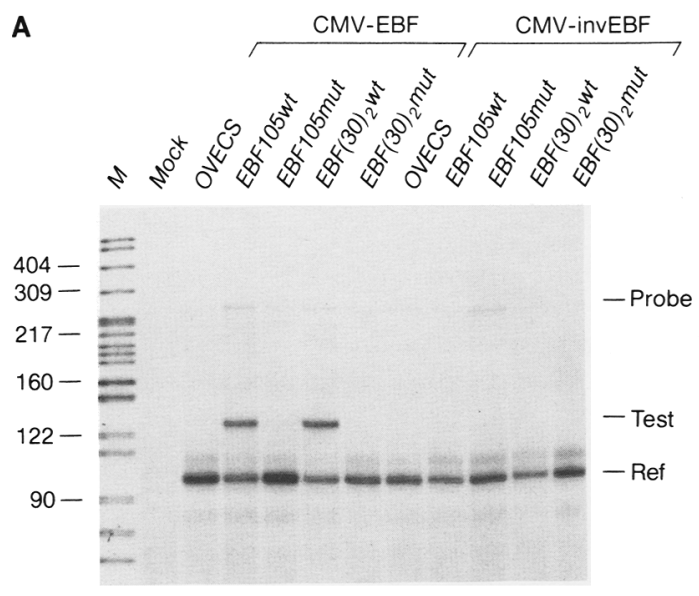

B

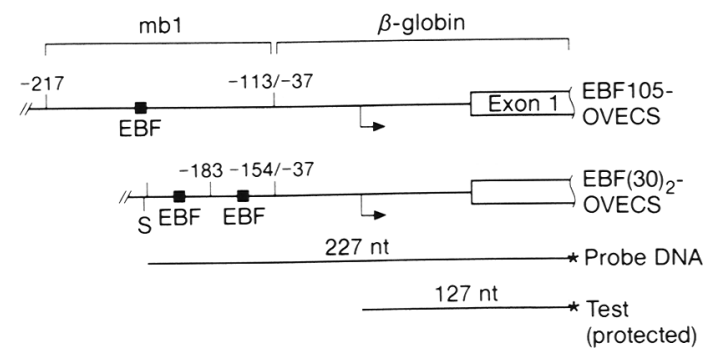

Figure 6. Transcriptional activation by recombinant EBF in nonlymphoid cells. (A) HeLa cells were transfected with effector plasmids for EBF expression, together with OVECS reporter plasmids and the OVEC-RF reference plasmid (Westin et al. 1987). Reporter plasmid inserts contained wild-type or mutated EBF-binding sites and are described in $B$. The unmodified OVECS vector was tested as a control. At $48 \mathrm{hr}$ post-transfection, total cellular RNA was isolated and analyzed by $\mathrm{S} 1 \mathrm{nu}$ clease protection using a $\beta$-globin probe specific for both the OVECS test and reference transcripts (shown in $B$ ). The effector plasmids CMV-EBF and CMV-invEBF contain the entire CDNA insert of $\phi E B F 17$ in the sense or antisense orientation, respectively. Correctly initiated $\beta$-globin transcripts are designated Test and transcripts derived from the reference plasmid, Ref. Residual undigested probe is indicated (Probe). (B) Schematic diagram of the OVECS reporter gene constructs, the probe for the S1 nuclease assay, and protected fragments. One set of reporter plasmids contained either one copy of the wild-type (EBF105wt) 105-bp mb-1 distal promoter fragment (nucleotides -217 to -113 ) or one copy of the fragment with a mutated EBF-binding site (EBF105mut). The second set contained two copies of either a synthetic oligonucleotide comprising the wild-type $\left[\mathrm{EBF}(30)_{2} \mathrm{wt}\right] \mathrm{mb}$-1 promoter EBF-binding site (nucleotides -183 to -154$)$ or a mutated site $\left[\operatorname{EBF}(30)_{2}\right.$ mut]. 
A

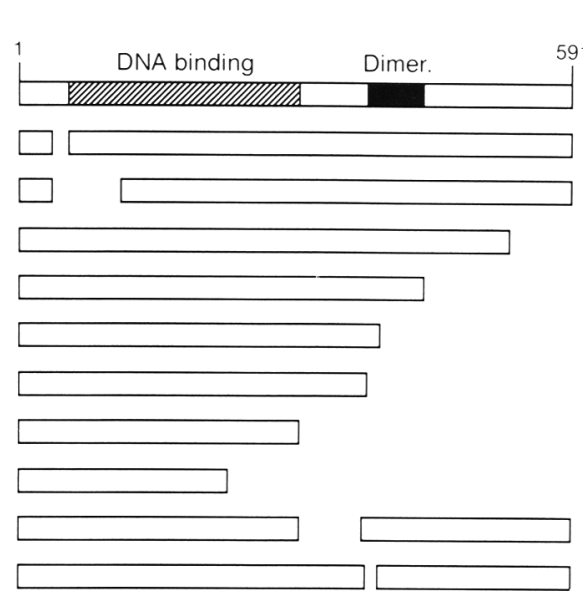

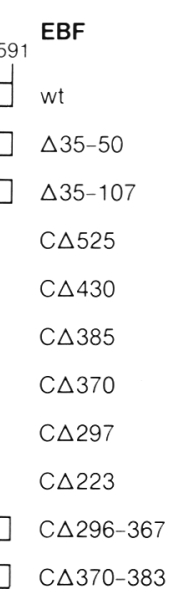

$\begin{array}{cc}\begin{array}{c}\text { DNA } \\ \text { binding }\end{array} & \text { Dimerization } \\ +++ & \mathrm{D} \\ ++ & \mathrm{D} \\ - & \\ +++ & \mathrm{D} \\ +++ & \mathrm{D} \\ + & \mathrm{M} \\ + & \mathrm{M} \\ + & \mathrm{M} \\ - & \\ ++ & \mathrm{D} \\ + & \mathrm{M}\end{array}$

M

Figure 7. Functional domains of EBF. $(A)$ Schematic representation of fulllength (wt) and truncated forms of EBF. Gaps indicate the deletion of amino acids. Boundaries of the deletions are indicated at right. DNA-binding column ranks the level of DNA binding by various forms of EBF in $B$ relative to the level of polypeptide synthesis detected in $C$. The dimerization column summarizes the interpretation of DNA binding by full-length and truncated EBF polypeptides as dimeric (D) or monomeric (M) proteins. $(B)$ Electrophoretic mobility retardation assay of DNA binding by full-length and truncated forms of recombinant EBF. Rabbit reticulocyte lysate was programmed with RNA transcripts encoding EBF for translation in vitro with unlabeled methionine. Translated polypeptides were incubated with a ${ }^{32} \mathrm{P}$-labeled $m b-1$ promoter probe and separated as described in Fig. 2 . All lanes except 4, 6, and 10 contain faster migrating minor complexes that probably result from internal translation initiation. $(F)$ Free probe. $|C|$ SDS-PAGE analysis of in vitro trans-

B

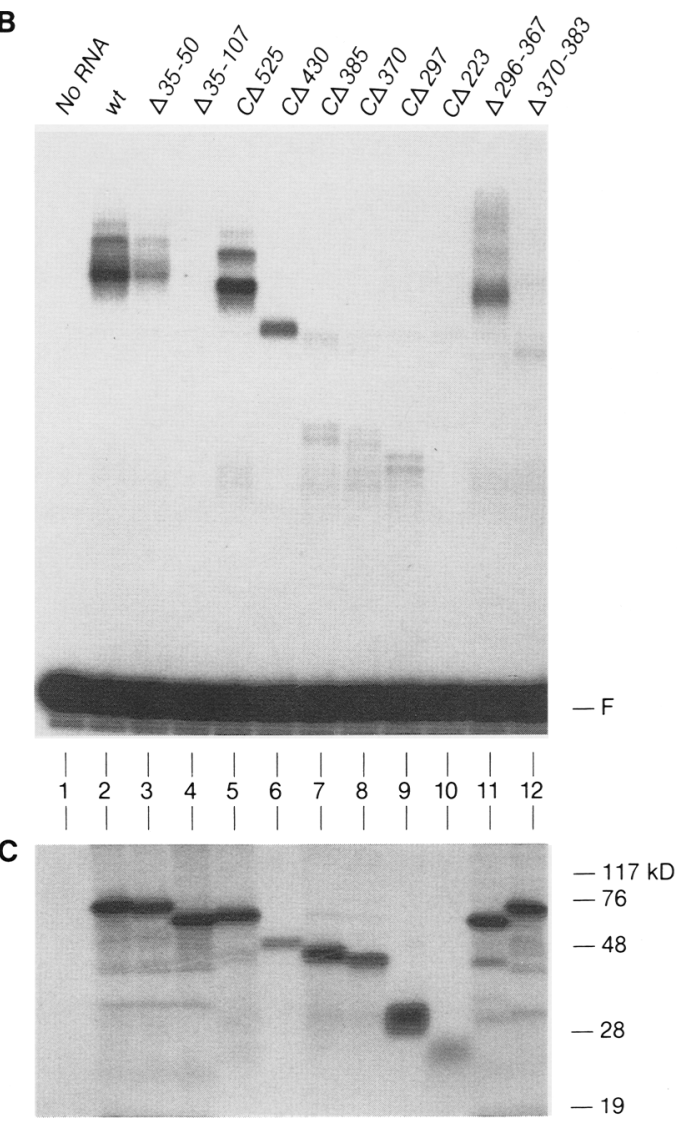
lated EBF polypeptides. Translation reactions were performed in parallel with $\left[{ }^{35}\right.$ Slmethionine and analyzed using $10 \%$ SDS-PAGE. Molecular size markers show the positions of prestained high molecular mass protein standards (Bethesda Research Laboratories). After correction for the number of methionines in each polypeptide [wt $\{18\}, \Delta 35-50(18), \Delta 35-107(18), C \Delta 525$ (16), C $\Delta 430$ (11), $C \Delta 385$ (10), $C \Delta 370$ (10), $C \Delta 297$ (9), $C \Delta 223$ (8), $\Delta 296-383$ (17), and $\Delta 370-383$ (18)], PhosphorImager analysis indicated that the concentration of ${ }^{35} \mathrm{~S}$-labeled EBF in translated preparations was roughly the same with the exception of $\mathrm{C} \Delta 430$ (fivefold less than wt) and $\mathrm{C} \Delta 223$ (fourfold less).

estimated in a parallel translation reaction containing $\left[{ }^{35} \mathrm{~S}\right]$-methionine, and the labeled products were analyzed by SDS-PAGE (Fig. 7C). The wild-type and truncated EBF proteins (Fig. 7A) were examined for binding to a labeled $m b-1$ promoter probe in the electrophoretic mobility retardation assay (Fig. 7B). Full-length EBF protein $(w t)$ formed one major and two slower migrating minor complexes with the $m b-1$ sequence (Fig. $7 \mathrm{~B}$, lane 2). A deletion of 16 amino acids near the amino terminus $(\Delta 35-50)$ reduced complex formation by a factor of $3 \mathrm{but}$ otherwise maintained the pattern of multiple proteinDNA complexes (lane 3). In contrast, a larger deletion ( $\Delta 35-107\}$ reduced complex formation to background levels, indicating that the region between Ala-50 and Gly-107 is essential for DNA binding (lane 4).

Progressive truncations from the carboxyl terminus of EBF suggested the presence of at least two functional domains. The deletion of amino acids carboxy-terminal of Ala-525 (C $\Delta 525$ ) had no obvious effect on DNA binding (Fig. 7B, lane 5). Deletion of additional amino acids to His-430 (C $\Delta 430)$ maintained the overall level of DNA binding but reduced the number of complexes to a single species (lane 6). Further carboxy-terminal truncations in mutants $C \Delta 385, C \Delta 370$, and $C \Delta 297$ greatly decreased the level of DNA binding ( $>50$-fold) relative to wild-type EBF and produced a different pattern of complexes (lanes 7-9|. Finally, no DNA binding was observed with the $\mathrm{C} \Delta 223$ deletion mutant of EBF. Together, these data suggest that EBF contains both a region between the aminoterminus and Thr-97 that is required for DNA binding and a more carboxy-terminal domain that greatly enhances the level of binding. To examine whether these two regions represent independent domains, we introduced an internal deletion of 72 amino acids between residues 296 and 367 . The internal deletion had only a small effect on both the level of DNA binding and the migration of protein-DNA complexes (lane 11), suggesting that the two domains are structurally independent.

Although a few complexes containing the $C \Delta 385$, $\mathrm{C} \Delta 370$, or $\mathrm{C} \Delta 297$ proteins migrated at a rate consistent with the extent of the deletions, the largest fraction of protein-DNA complexes containing these truncated polypeptides migrated at a significantly faster rate /cf. lanes $7-9$ with lanes $2,3,5$, and 6$)$. The carboxy-terminal 
region deleted from these mutants includes two nearly identical (12 of 15) amino acid repeats (Table 2). The repeats possess significant similarity with the amino acid sequences of helix 2 motifs of the bHLH proteins MyoD, the related Drosophila myogenic factor nautilus, and members of the Myc family. To directly assess the role of these repeats in EBF for DNA binding, 14 amino acids within this region (C $\triangle 370-383)$ were deleted. DNA binding was greatly reduced relative to full-length EBF (Fig. 7B, cf. lanes 2 and 12), confirming the functional importance of the deleted amino acids. Moreover, complexes containing the $63-\mathrm{kD} \mathrm{C} \Delta 370-383$ polypeptide migrated faster than those formed with the $\mathrm{C} \Delta 430$ polypeptide (lane 6), which has a molecular mass of $48 \mathrm{kD}$. These data suggest that the amino acid repeat sequences enhance the level of DNA binding by mediating the formation of multimeric EBF complexes.

\section{EBF binds DNA as a homodimer}

Gel filtration experiments determined for native EBF a radius of gyration equivalent to a $140-\mathrm{kD}$ globular protein, which is consistent with the size of a putative homodimeric complex (Travis et al. 1993). To investigate the stoichiometry of EBF in complex with DNA, we examined whether recombinant EBF proteins of different lengths can form heterodimeric complexes. Full-length or truncated $(C \Delta 430)$ EBF polypeptides were translated separately or together in vitro and examined for DNA binding in an electrophoretic mobility retardation assay (Fig. 8). The binding of full-length EBF resulted in protein-DNA complexes with slower mobilities relative to the complex obtained with truncated EBFC $\Delta 430$ (Fig. $8 \mathrm{~A}$, cf. lane 2 with lane 4$)$. When appropriate amounts of RNA encoding the two proteins were translated together, an additional complex with intermediate mobility was detected, indicating the formation of heterodimers containing both EBF polypeptides (lane 3). Heterodimeric complexes of full-length and truncated EBF polypeptides were detected only when translated together but not when the two polypeptides were translated separately and mixed prior to the addition of the
DNA probe (lane 7). These results suggest that the wildtype EBF polypeptides bind the site in the $m b-1$ promoter as a homodimer. Moreover, the lack of heterodimer formation following the mixing of separate translation products suggests that EBF exists as stable multimers in solution. Homodimeric complexes are the predominant species observed in electrophoretic mobility retardation assays, although higher order complexes with slower mobilities can form with wild-type EBF.

To analyze further the role of the direct repeats for dimerization, we deleted residues 370-383 from EBFC$\Delta 430$ and examined the ability of the resulting polypeptide $[\mathrm{EBFC} \Delta 430(\Delta \mathrm{H} 1)]$ to heterodimerize with full-length EBFwt. In contrast to the EBFC $\Delta 430$ polypeptide, in vitro-translated EBFC $\Delta 430(\Delta \mathrm{H} 1)$ polypeptide alone bound the $m b-1$ promoter probe at nearly undetectable levels (Fig. 8A, lane 6). When translated together, EBFwt and EBFC $\Delta 430(\Delta \mathrm{H} 1)$ did not form complexes with intermediate mobilities, and the level of complex formation by EBFwt was undiminished (lane 5). As a control, SDSPAGE analysis of ${ }^{35} \mathrm{~S}$-labeled polypeptides showed that the EBFC $\Delta 430$ and EBFC $\Delta 430(\Delta \mathrm{H} 1)$ polypeptides were synthesized at similar levels (Fig. 8B, lanes 4,6). Together, our data suggest that residues $370-383$, which include part of one of the repeats in EBF, are important for DNA binding and dimerization.

\section{Discussion}

Here, we describe the isolation of cDNAs that encode EBF, a novel transcriptional activator of the early B-cellspecific $m b-1$ gene. The identification of the polypeptide encoded by the cDNAs as EBF is supported by multiple criteria. First, the calculated molecular mass of the cDNA-encoded polypeptide $(64.4 \mathrm{kD})$ is in close agreement with the estimated molecular mass of purified EBF on SDS-PAGE (62-65 kD). Second, recombinant polypeptides translated from the cDNAs have the same DNA-binding specificity. Moreover, both proteins formed complexes with DNA that migrate in electrophoretic mobility retardation assays with the same mobility as EBF in nuclear extracts. Third, contacts between re-

Table 2. Similarity between amino acid repeats in EBF and bHLH domains

\begin{tabular}{|c|c|c|c|}
\hline $\mathrm{EBF}^{\mathrm{a}}$ & $\begin{array}{l}375 \\
397\end{array}$ & $\begin{array}{l}\text { K E V ILKRAAD L V E A L YGMPHNN } \\
\text { E + ILKRAAD + + E A L Y P N } \\
\text { QE I ILKRAAD I A E ALY S VPRNH }\end{array}$ & $\begin{array}{l}396 \\
418\end{array}$ \\
\hline Consensus $^{\mathrm{b}}$ & & A $\Psi \quad \mathrm{Y} \Psi$ & \\
\hline Nautilus ${ }^{\mathrm{c}}$ & 194 & $\begin{array}{l}\text { QR L PKVE I L R N A I E Y I E S LE } \\
\text { RLPK IL }+\mathrm{A}+++\mathrm{E} \text { L }\end{array}$ & 213 \\
\hline EBF & 371 & $\begin{array}{l}\text { E R L PKEVILKRA A DLVEALY } \\
\begin{array}{l}\text { + }+ \text { PK VILK }+A+V \\
\text { V }\end{array}\end{array}$ & 391 \\
\hline $\mathrm{v}-\mathrm{Myc}^{\mathrm{d}}$ & 388 & E K A PKVVILKKATEYVL SLQ & 406 \\
\hline
\end{tabular}

aThe amino acid sequence of EBF between residues 375 and 418 is aligned to show the presence of two repeats of a conserved sequence. Identical amino acids are shown between lines. $\{+\mid$ Amino acid similarity.

${ }^{b}$ bHLH domain helix 2 consensus (Vinson and Garcia 1992). ( $\Psi$ ) Hydrophobic amino acids.

cMichelson et al. (1990).

dAlitalo et al. (1983). 


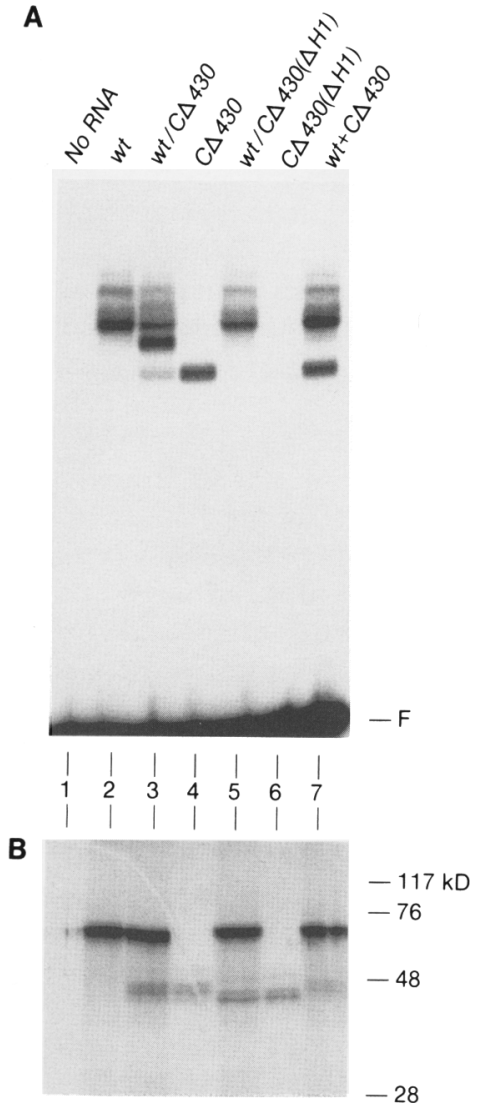

Figure 8. EBF binds DNA as a homodimer. $(A)$ Electrophoretic mobility retardation assay of DNA binding by full-length and truncated EBF polypeptides. The proteins were translated sequentially or together in vitro, incubated with a labeled $m b-1$ promoter probe, and bound and free probe was separated as in Fig. 2. The DNA-binding reactions contained wild-type EBF alone (lane 2), wild-type EBF cotranslated with $C \Delta 430$ or $\mathrm{C} \Delta 430(\Delta \mathrm{H} 1$ ) (lanes 3,5$)$, or a mixture of wild-type and $\mathrm{C} \Delta 430$ proteins following separate translations (lane 7). DNA-binding reactions with $\mathrm{C} \Delta 430$ or $\mathrm{C} \Delta 430(\Delta \mathrm{H})$ alone are shown in lanes 4 and 6, respectively. (F) Free probe. (B) SDS-PAGE analysis of in vitro translated EBF polypeptides. Translation reactions were performed in parallel with $\left[{ }^{35} \mathrm{~S} \mid\right.$-labeled methionine and analyzed using 10\% SDS-PAGE. Molecular size markers indicate the position of prestained high molecular mass protein standards.

combinant $\mathrm{EBF}$ and the $m b \cdot 1$ promoter-binding site are nearly identical with those observed previously with EBF in nuclear extracts. Fourth, the EBF cDNA hybridizes with mRNAs only from cell lines that contain EBF DNA-binding activity. Finally, overexpression of recombinant EBF in nonlymphoid cells can activate the expression of a heterologous promoter containing binding sites for EBF.

We identified at least two functional domains in EBF, including an amino-terminal region that is essential for DNA binding and a separate carboxy-terminal region that is required for efficient dimerization. Deletion of the region between the DNA-binding and dimerization domains (Gly-296 and Pro-367) had only a very small effect on DNA binding, indicating the structural independence of the two domains. The function of the spacer region has not yet been determined, but it may impart flexibility between the two domains. This configuration of domains is similar to that of the estrogen receptor, a nuclear hormone receptor family member, which contains an amino-terminal DNA-binding domain and a carboxy-terminal dimerization domain separated by an extended 250-amino-acid spacer region that is dispensable for a high level of DNA binding (Lees et al. 1990).

\section{The EBF DNA-binding domain}

Amino-terminal and carboxy-terminal truncations of EBF delineated the DNA-binding domain to a region of at least 223 amino acids. This region does not show any extensive homology with known families of DNA-binding proteins and does not contain clustered basic amino acids. The DNA-binding domain, however, has a very high density of cysteine residues, and seven are clustered within 58 amino acids of the amino-terminal domain. The spacing of these residues, together with the presence of only a single histidine in this region, suggests that the clustered cysteine residues do not form typical Cys-His zinc finger structures (for review, see Berg 1990), such as those observed in the transcription factors TFIIIA (Miller et al. 1985; Brown et al. 1985) and Spl (Kadonaga et al. 1987). Moreover, no obvious homology was found with other cysteine-rich domains, including the LIM domains (Freyd et al. 1990), the cysteine clusters of RAG-1 and related genes (Freemont et al. 1991), and the metal-binding domains of the steroid receptor family (for review, see Evans 1988). A small, but possibly significant, homology was detected between EBF and fungal transcription factors that contain Cys-Cys zinc fingers. Both EBF and the transcriptional activator protein GAL4 of Saccharomyces cerevisiae contain a motif consisting of CXXCXKK, which has been shown to participate in the formation of one zinc finger in GAL4 (Baleja et al. 1992; Kraulis et al. 1992; Marmorstein et al. 1992). Moreover, mutation of these cysteines in EBF to serines abrogated DNA binding, demonstrating the functional importance of these residues (J. Hagman, unpubl.).

\section{EBF contains a new type of dimerization domain}

Cotranslation experiments with wild-type and truncated EBF polypeptides indicated the formation of stable homodimers, and this subunit composition is consistent with the estimated molecular mass of $140 \mathrm{kD}$ for native EBF. Analysis of deletion mutants of EBF indicated that the region between Pro- 370 and His- 430 is essential for efficient dimerization and DNA binding. A notable feature of the amino acid sequence of this domain is a repeat of 15 amino acids (Table 2). Comparison of this sequence with the protein sequence data base revealed an identity of 8 of 15 residues with the rat liver mitochondrial enzyme fumarate hydratase (Suzuki et al. 1989|; however, we have not been able to attach any 
functional significance to this homology. More significantly, the sequence comparison revealed a high degree of similarity between the EBF repeats and the consensus sequence for helix 2 of bHLH domains /Vinson and Garcia 1992), which was shown to be required for dimerization and DNA binding of bHLH proteins (Murre et al. 1989; Davis et al. 1990; Voronova and Baltimore 1990). The homology extends into the variable loop sequences between helices 1 and 2 of the bHLH domain, but does not include helix 1 or the adjacent basic region. The best matches (Table 2) were found between the EBF repeats and the Drosophila myogenic factor nautilus (Michelson et al. 1990) and murine MyoD (Davis et al. 1987), and members of the Myc basic helix-loop-helix zipper family, including v-Myc (Alitalo et al. 1983) and N-Myc (DePinho et al. 1986).

The EBF repeats are predicted by secondary structure analysis to have high probability to fold as amphipathic $\alpha$-helices (Chou and Fasman 1978), and each repeat contains extensive hydrophobic surfaces that could be available for helix-helix interactions. Although the primary sequences of the putative helical repeats share many residues with both Myc and MyoD-like proteins, significant differences prevent the classification of EBF together with the bHLH family polypeptides. First, the EBF dimerization domain contains a duplication of a putative helix motif, whereas members of the bHLH family contain dissimilar helix 1 and helix 2 motifs. Second, the putative helical repeat sequences of EBF differ from the bHLH consensus at three positions that are completely conserved among helix 2 sequences of various bHLH proteins. In particular, EBF lacks the invariant tyrosine residue and has Glu-Val in place of the bHLH consensus $\Psi-$ Glu (Vinson and Garcia 1991). Therefore, the EBF repeats may form a structure different from that suggested for the bHLH domains. Moreover, the repeats in EBF are not flanked by an identifiable basic region. Instead, EBF has a distinct amino-terminal DNA-binding domain. The function of the repeats in EBF for dimerization is still obscure. The repeats may allow for dimerization independently of other sequences in EBF. Alternatively, the repeats could stabilize inefficient dimerization of the DNA-binding domain.

The homodimeric composition of EBF is reflected in the recognition of a palindromic nucleotide sequence. We have recently used affinity-purified EBF to characterize its DNA-binding specificity (Travis et al. 1993). A set of mutations in the EBF-binding site of the $m b-1$ promoter indicated that the protein recognizes variations of the palindromic sequence 5'ATTCCCNNGGGAAT. The nucleotide sequence 5 '-GGGAAT was selected as a preferred half-site for EBF binding using a selection and amplification assay with oligonucleotides containing randomized bases /described in Blackwell and Weintraub 1990). Binding to the perfect palindrome of this half-site was eightfold higher than to the imperfect palindrome 5'-AGACTCAAGGGAAT found in the $m b-1$ promoter (Travis et al. 1993). Consistent with the presence of optimal right-hand half-site (5'-GGGAAT) and a weak lefthand half-site $\left(5^{\prime}\right.$-GAGTCT) in the EBF binding site of the $m b-1$ promoter, methylation interference with recombinant EBF detected contacts with all residues of the perfect right-hand half-site and only one residue of the left hand site. Moreover, DNA binding by truncated EBF proteins lacking the dimerization region required only the right-hand half-site, $5^{\prime}$-GGGAAT (J. Hagman, unpubl.). The geometry of the EBF-binding site as an inverted repeat of hexamers separated by a 2-bp spacer is reminiscent of the response elements of homodimeric steroid and thyroid hormone receptors, suggesting the possibility of a structural relationship between these nuclear receptors and EBF (Klock et al. 1987; Martinez et al. 1987; Glass et al. 1988).

\section{The role of EBF in cell type-specific gene expression}

Our analysis confirms that within the B-cell lineage, EBF is expressed during the early stages of B-cell differentiation, including pre-B and $\mathrm{mIg}^{+} \mathrm{B}$ cells, and not in other types of hematopoietic cells. The analysis of mouse tissue mRNAs suggests that the EBF gene is also expressed in a number of nonlymphoid tissue types. The abundance of EBF transcripts in adipose tissue was equal to the level observed in spleen, whereas low levels of EBF transcripts were detected in brain, heart, skeletal muscle, and kidney. Because the assay was performed with mRNA derived from whole organs, low-level expression may actually reflect high-level expression by a subset of cells in a given tissue. In addition, it is important to note that the DNA probe used in the S1 nuclease protection assay contained only a portion of the EBF cDNA sequence and did not discriminate between the multiple EBF transcripts identified in B cells. Further analysis of the cell-type distribution of EBF expression will depend on direct visualization by use of in situ hybridization with EBF-specific probes or on staining tissues with antiEBF antisera.

Expression of EBF in nonlymphoid cells augments transcription of reporter genes containing functional EBF-binding sites 30 -fold. Thus, EBF appears to be an important activator of transcription in B lymphocytes. The experiment also suggests that no other B-cell-specific protein is necessary for EBF activity. Earlier experiments suggested that the EBF-binding site activated transcription in a context-dependent manner, because flanking distal $m b-1$ promoter sequences were required to enhance transcription from a heterologous promoter in transfected PD36 pre-B cells (Hagman et al. 1991). In contrast, activation by recombinant EBF could be observed with EBF-binding sites alone in HeLa cells. One possible explanation for this difference is that the level of expression of recombinant EBF in transfected $\mathrm{HeLa}$ cells is higher than that of the endogenous protein in PD36 cells. Alternatively, the SV40 enhancer region downstream of the $\beta$-globin gene in the OVECS reporter plasmids may functionally substitute for $m b-1$ promoter distal region sequences.

EBF is one of two nuclear factors that are expressed in early B lymphocytes and are candidate regulators of tissue- and stage-specific genes. The other factor, termed 
BSAP (Barberis et al. 1991), is the product of the Pax-5 gene and interacts with DNA through a Pax homeo domain motif (Adams et al. 1992). In addition to early B cells, EBF and BSAP transcripts can be detected in a few nonlymphoid tissues. BSAP expression was observed in testis and the developing central nervous system, whereas EBF transcripts were detected in adipocytes. BSAP has been implicated in the regulation of the early B-cell-specific CD19 gene (Kozmik et al. 1992). Similarly, EBF is a likely regulator of the $m b-1$ gene, which like $C D 19$, encodes a protein that is involved in differentiation stage-specific transmembrane signaling in early B cells (for review, see Cambier 1991; Reth 1991). Finally, expression of both factors is shut off following terminal differentiation to the plasma cell stage (Barberis et al. 1991; Hagman et al. 1991). We have been unable to detect binding of BSAP to the $m b-1$ promoter and did not identify any EBF-binding site sequences in the $C D 19$ promoter (J. Hagman, unpubl.; M. Busslinger, pers. commu.). Thus, these two factors may regulate distinct sets of genes at early stages of the B-cell lineage. Alternatively, EBF or BSAP may regulate gene expression as part of a regressive hierarchy of transcriptional control. With the cloning of cDNAs encoding EBF it will be possible to examine the biological role of this protein in B-cell differentiation and mouse development by the generation of mice containing homozygous disruptions of the EBF gene.

\section{Materials and methods}

Protein purification and amino acid sequence analysis

The purification of EBF from 38B9 pre-B cell crude nuclear extracts is described elsewhere (A. Travis, J. Hagman, L. Hwang, and R. Grosschedl, in prep.). Approximately $25 \mu \mathrm{g}$ of affinity column-purified p62-65 was precipitated with an equal volume of $50 \%$ trichloroacetic acid, washed with acetone, fractionated by $10 \%$ SDS-PAGE, stained with Coomassie blue to localize the p62-65 fraction, and electroeluted as described previously (Hunkapiller et al. 1983). The protein sample was precipitated with $90 \%$ acetone for $24 \mathrm{hr}$ at $-20^{\circ} \mathrm{C}$, redissolved in $50 \mu \mathrm{l}$ of 0.4 $\mathrm{M} \mathrm{NH}_{4} \mathrm{HCO}_{3} / 8 \mathrm{M}$ urea, reduced with $5 \mathrm{mM}$ DTT at $50^{\circ} \mathrm{C}$ for 15 $\mathrm{min}$, and carboxymethylated with $10 \mathrm{~mm}$ iodoacetic acid at room temperature for $15 \mathrm{~min}$. The sample was diluted to $200 \mu \mathrm{l}$ with water and trypsin (sequencing grade; Boehringer Mannheim Biochemicals, Indianapolis, IN) was added at an enzyme /substrate ratio of $1: 25$. The sample was digested at $37^{\circ} \mathrm{C}$ for $24 \mathrm{hr}$, acidified with trifluoroacetic acid (TFA), and chromatographed using a reverse-phase HPLC column $\mid \mathrm{Cl}$ 8, 2.1 $\mathrm{mm} \times 25 \mathrm{~cm}$; Applied Biosystems, Foster City, CA) equilibrated with $0.1 \%$ TFA (Sequenal grade; Pierce Chemical, Rockford, Il) in water at a flow rate of $0.25 \mathrm{ml} / \mathrm{min}$. The peptides were eluted with a 90 -min gradient of $0.1 \%$ TFA $/ 90 \%$ acetonitrile. Amino-terminal sequence analysis of the tryptic peptides was carried out on a model $470 \mathrm{~A}$ gas phase sequencer equipped with a model 120A on-line PTH-amino acid analyzer and a model 900A data analysis station using version 1.20 (Applied Biosystems, Inc.).

\section{cDNA cloning}

Degenerate oligonucleotides were synthesized to encode sense and antisense sequences containing all possible codons for the amino acids indicated in Table 1. Oligonucleotides were used to amplify specific sequences from a pre-B-cell (38B9) cDNA library (Rudin et al. 1990) using the PCR method. Library DNA (800ng) was combined with appropriate pairs of oligonucleotide mixtures $(0.5 \mu \mathrm{g})$ and amplified with AmpliTaq DNA polymerase (Perkin-Elmer Cetus, Emeryville, CA) for 30 cycles, each consisting of $2 \mathrm{~min}$ at $94^{\circ} \mathrm{C} ; 2 \mathrm{~min}$ at $48^{\circ} \mathrm{C}_{j}$ and $2 \mathrm{~min}$ at $72^{\circ} \mathrm{C}$. The PCR product was subcloned into Bluescript KS + (Stratagene, La Jolla, CA) to generate $\mathrm{pEBF} 11$, and the sequence was determined using the dideoxy chain termination method (Sambrook et al. 1989).

For the isolation of longer cDNA clones, the insert of $\mathrm{pEBF} 11$ was radiolabeled by nick translation and hybridized to a pre-Bcell (70Z/3) cDNA library in $\mathrm{kgt} 11$ (Ben-Neriah et al. 1986) as described previously (Travis et al. 1991a). The cDNA insert of $\phi \mathrm{EBF} 17$ was subcloned as an EcoRI fragment into Bluescript $\mathrm{KS}+$ for DNA sequencing (pEBF17). The cDNA insert was translated in all three reading frames and compared with the combined protein sequence data bases (PIR, SWISSPROT, and GENPEPT) of the National Center for Biotechnology Information by use of the BLASTP version 1.2.5 algorithm (Altschul et al. 1990].

\section{Plasmids}

Plasmids pEBF $\triangle 35-50$ and pEBF $\triangle 35-107$ were generated by cleavage of pEBF17 with KasI and either XmaI or BamHI, respectively, filling in with Klenow, and religation to delete the intervening sequences. A translation termination codon was inserted in place of His-430 by use of PCR and oligonucleotides $5^{\prime}$ - GTGGAAGCAGTATGAAGCTCGAGCCGCTGGGCAGC GG and 5'-CATCTACACAGCACTCAATG, and the fragment was ligated into the EcoRV site of Bluescript KS +, digested with BgIII and EcoRI, and ligated with the BgIII-EcoRI fragment of pEBF1 1 to make pEBFC $\triangle 430$. pEBFC $\triangle 223$ was constructed by fusion of the filled-in (Klenow) BstEII-XhoI fragment of pEBF17 with pEBF17 that had been cut with Asp 718 and similarly filled in. pEBF $\triangle 296-367$ was generated by fusion of a blunted iT4 DNA polymerase) KpnI site with the filled-in (Klenow) BstEII site of pEBF17. pEBFC $4430(\Delta \mathrm{H1})$ and pEBF $\Delta 370-383$ were generated by cleavage of either pEBFC 430 or pEBF 17 , respectively, with BstEII and BglII, filling in with Klenow, and religation.

The OVECS and OVEC-RF vectors were provided by $M$. Müller and W. Schaffner (Müller et al. 1988; Westin et al. 1987). To construct the wild-type (OVECS105wt) and mutant (OVECS $105 \mathrm{mut}$ ) reporter plasmids, the 105-bp StuI-NdeI fragments of pmblBH and pMX63 (Hagman et al. 1991) were filled in with Klenow and inserted into the Sall site (filled-in) at -37 of the $\beta$-globin promoter in OVECS. Two pairs of synthetic oligonucleotides (EBF30wt and EBF30mut) containing wild-type and mutated (m3) EBF sites (Hagman et al. 1991) were phosphorylated with T4 polynucleotide kinase and ligated head-to-tail into the Sall site of the OVECS vector:

\section{(EBF30WT)}

TCGAGAGAGACTCAAGGGAATTGTGGCCAGCC CTCTCTGAGTTCCCTTAACACCGGTCGGAGCT

(EBF30MUT)

TCGAGAGAGACTCAA c c G t t TTGTGGCCAGCC CTCTCTGAGTT g g $\mathrm{C}$ a AACACCGGTCGGAGCT

Single-stranded pEBF17 DNA was mutated at the amino terminus by use of the oligonucleotide $5^{\prime}$-GTGGAAGCAGTATGAAGCTCGAGCCGCTGGGCAGCGG and the method of Kunkel (1985) to make EBFXho4. CMV-EBF and CMV-invEBF were constructed by inserting the filled-in (Klenow) XhoI-XhoI 
fragment of EBFXho4 (encoding amino acids 18 - 591) in the sense or antisense orientation into the Asp 718 site (bluntended/ of the cytomegalovirus enhancer/promoter expression vector pEVRF1 (Matthias et al. 1989).

In vitro translation, DNA binding, electrophoretic mobility retardation assays, $S D S-P A G E$, and methylation interference

In vitro transcription, purification of transcripts, and translation using rabbit reticulocyte lysate (Promega) were described previously (Hagman and Grosschedl 1992). In vitro DNA binding and electrophoretic mobility retardation assays were performed as usual (Hagman et al. 1991), except that $20 \mu \mathrm{g} / \mathrm{ml}$ sheared salmon sperm DNA was used as a competitor for nonspecific binding. For the synthesis of EBF proteins with progressive carboxy-terminal deletions, pEBF17 was linearized with

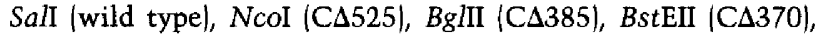
and $M s c I(C \Delta 223)$ before transcription with T7 RNA polymerase in vitro. The plasmids EBFC $\Delta 223, \mathrm{EBFC} \Delta 430, \mathrm{EBF} \Delta 35-30$, EBF $\Delta 35-107$, and EBFC $\Delta 430(\Delta \mathrm{H} 1)$ were all linearized with SalI. The efficiency of in vitro translation was assessed by SDS-PAGE of parallel translation reactions performed in the presence of $\left.{ }^{35} \mathrm{~S}\right]$ methionine (Amersham).

Methylation interference analysis was performed as described previously (Hagman et al. 1991), except that full-length recombinant EBF was generated by translation in vitro. Reference reactions $(G+A)$ were performed as described (Sambrook et al. 1989 .

\section{RNA blot and S1 nuclease protection analysis of EBF transcripts}

The selection of poly $(A)^{+}$RNA from cytoplasmic RNA using oligo-(dT) column chromatography, electrophoresis, and blotting of RNA, and the $\beta$-actin-specific probe were previously described (Travis et al. 1991a). Probes were labeled for hybridization by nick translation with $\left[\alpha^{-32} \mathrm{P}\right] \mathrm{dCTP}$.

Total cellular RNA was isolated from fresh tissue from 10- to 15-week-old mice, and S1 nuclease analysis was performed as described (Travis et al. 1991a). The single-stranded DNA probe for the detection of EBF transcripts was generated by $5^{\prime}$-endlabeling an antisense oligonucleotide corresponding to nucleotides $454-435$ of EBF (5'-GTTTTGTCATGGAGTCGATG), hybridization to a Bluescript $\mathrm{KS}+$ vector containing the BamHI-EcoRI fragment of pEBF17, extension with Klenow DNA polymerase, cleavage with $S a c I$ in the polylinker region, and purification of probe DNA on a denaturing polyacrylamide gel. The single-stranded probe for the detection of $I g \kappa$ lightchain transcripts was described previously (Jenuwein and Grosschedl 1991). To detect rRNA, total RNA was stained with ethidium bromide and electrophoresed as described (Fourney et al. 1988).

\section{Transfection of tissue culture cells and S1 analysis}

HeLa cells were grown in Joklik's medium supplemented with $10 \%$ fetal bovine serum. Transient DNA transfections were performed with $1.5 \mu \mathrm{g}$ each of reporter and CMV-effector plasmids together with $0.4 \mu \mathrm{g}$ of reference plasmid (OVEC-RF) using the DEAE-dextran/chloroquine procedure (Travis et al. 1991a). At $48 \mathrm{hr}$ post-transfection, cytoplasmic RNA was isolated, and specific transcripts were analyzed by $\mathrm{S} 1$ nuclease protection assays (Travis et al. 1991b).

For S1 nuclease analysis, the OVECS-specific DNA probe was prepared by extension of a $5^{\prime}$-end-labeled oligonucleotide $15^{\prime}$ CCAACTTCTTCCACATTC encompassing nucleotides + 110 to +127 of the first exon of the rabbit $\beta$-globin reporter gene. Correctly initiated transcripts derived from the $\beta$-globin promoter were detected as 127 -bp protected fragments. Transcripts from the reference plasmid OVEC-RF were detected as 107-bp protected fragments.

\section{Acknowledgments}

We are indebted to Keith Yamamoto, Robert Davis, and James Fraser for their reviews of this manuscript. We thank John Pagel and Klaus Giese for helpful comments and discussion, Rong-guo Qui and Victoria Davis for technical assistance, Leslie Taylor for comparison of the EBF sequences with protein sequence data bases. We also thank J. Peter Engler for providing the 38B9/ CDM8 cDNA library and Michael Müller for providing the OVECS plasmids. We acknowledge the assistance of Lori Hansen with sequence analysis. J.H. is the recipient of a postdoctoral fellowship from the Leukemia Society of America. C.B. is supported by a postdoctoral fellowship from Fonds pour la formation du Chercheurs et l'Aide a la Recherche (FCAR). This work was supported by funds from the Howard Hughes Medical Institute.

The publication costs of this article were defrayed in part by payment of page charges. This article must therefore be hereby marked "advertisement" in accordance with 18 USC section 1734 solely to indicate this fact.

\section{Note added in proof}

The nucleotide sequence data reported in this paper have been submitted to the GenBank data library under accession number L.12147.

\section{References}

Adams, B., P. Dorfler, A. Aguzzi, Z. Kozmik, P. Urbanek, I. Maurer-Fogy, and M. Busslinger. 1992. Pax-5 encodes the transcription factor BSAP and is expressed in B lymphocytes, the developing CNS, and adult testis. Genes \& Dev. 6: 15891607.

Alitalo, K., J.M. Bishop, D.H. Smith, E.Y. Chen, W.W. Colby, and A.D. Levinson. 1983. Nucleotide sequence of the v-myc oncogene of avian retrovirus MC29. Proc. Natl. Acad. Sci. 80: $100-104$

Altschul, S.F., W. Gish, W. Miller, E.W. Myers, and D.J. Lipman. 1990. Basic local alignment search tool. /. Mol. Biol. 215: 403-410.

Baleja, J.D., Marmorstein, R., S.C. Harrison, and G. Wagner. 1992. Solution structure of the DNA-binding domain of $\mathrm{Cd}_{2}$ GAL4 from $S$. cerevisiae. Nature 356: 450-453.

Barberis, A., K. Widenhorn, L. Vitelli, and M. Busslinger. 1990. A novel B-cell lineage-specific transcription factor present at early but not late stages of differentiation. Genes \& Dev. 4: 849-859.

Ben-Neriah, Y., A. Bernards, M. Paskind, G.Q. Dailey, and D. Baltimore. 1986. Alternative 5' exons in c-abl mRNA. Cell 44: 577-586.

Berg, J.M. 1990. Zinc fingers and other metal-binding domains. I. Biol. Chem. 265: 6513-6516.

Blackwell, T.K. and H. Weintraub. 1990. Differences and similarities in DNA-binding preferences of MyoD and E2A protein complexes revealed by binding site selection. Science 250: $1104-1110$.

Brown, R.S., C. Sander, and P. Argos. 1985. The primary structure of transcription factor TFIIIA has 12 consecutive repeats. FEBS Lett. 186: 271-274. 
Cambier, J.C. 1991. Capturing antigen receptor components. Curr. Biol. 1: 25-27.

Campbell, K.S. and J.C. Cambier. 1990. B lymphocyte antigen receptors $(\mathrm{mIg})$ are non-covalently associated with a disulfide-linked, inducibly phosphorylated glycoprotein complex. EMBO J. 9: 441-448.

Chou, P.Y. and G.D. Fasman. 1978. Prediction of the secondary structure of proteins from their amino acid sequence. $A d v$. Enzymol. 47: 45-148.

Davis, R.L., H. Weintraub, and A.B. Lassar. 1987. Expression of a single transfected cDNA converts fibroblasts to myoblasts. Cell 51: 987-1000.

Davis, R.L., P.-F. Cheng, A.B. Lassar, and H. Weintraub. 1990. The MyoD DNA binding domain contains a recognition code for muscle-specific activation. Cell 60: 733-746.

DePinho, R.A., E. Legouy, L.B. Feldman, N.E. Kohl, G.D. Yancopolous, and F.W. Alt. 1986. Structure and expression of the murine N-myc gene. Proc. Natl. Acad. Sci. 83: 1827-1831.

Evans, R.M. 1988. The steroid and thyroid hormone receptor superfamily. Science 240: 889-895.

Feldhaus, A.L., D. Mbangkollo, K.L. Arvin, C.A. Klug, and H. Singh. 1992. BLyf, a novel cell-type- and stage-specific regulator of the B-lymphocyte gene mb-1. Mol. Cell. Biol. 12: 1126-1133.

Freemont, P.S., I.M. Hanson, and J. Trowsdale. 1991. A novel cysteine-rich sequence motif. Cell 64: 483-484.

Freyd, G., S.K. Kim, and H. R. Horvitz. 1990. Novel cysteinerich motif and homeodomain in the product of the Caenorhabditis elegans cell lineage gene lin-11. Nature 344: 876-879.

Fourney, R.M., J. Miyakoshi, R.S. Day III, and M.C. Paterson. Northern blotting: Efficient RNA staining and transfer. 1988. Focus 10: 5-7.

Glass, C.K., J.M. Holloway, O.V. Devary, and M.G. Rosenfeld. 1988. The thyroid hormone receptor binds with opposite transcriptional effects to a common sequence motif in thyroid hormone and estrogen response elements. Cell 54: 313 323.

Hagman, J. and R. Grosschedl. 1992. An inhibitory carboxylterminal domain in Ets-1 and Ets-2 mediates differential binding of ETS family factors to promoter sequences of the mb-1 gene. Proc. Natl. Acad. Sci. 89: 8889-8893.

Hagman, J., A. Travis, and R. Grosschedl. 1991. A novel lineagespecific nuclear factor regulates $m b-1$ gene transcription at the early stages of B cell differentiation. EMBO J. 10: 3409 3417.

Herskowitz, I. 1989. A regulatory hierarchy for cell specialization in yeast. Nature 342: 749-757.

Hombach, I., T. Tsubata, L. Leclercq, H. Stappert, and M. Reth. 1990. Molecular components of the B-cell antigen receptor complex of the IgM class. Nature 343: 760-762.

Hunkapiller, M.W., E. Lujan, F. Ostrander, and L. Hood. 1983. Isolation of microgram quantities of proteins from polyacrylamide gels for amino acid sequence analysis. Methods Enzymol. 91: 227-236.

Jenuwein, T. and R. Grosschedl. 1991. Complex pattern of immunoglobulin $\mu$ gene expression in normal and transgenic mice: Nonoverlapping regulatory sequences govern distinct tissue specificities. Genes \&) Dev. 5: 932-943.

Kadonaga, J.T. and R. Tjian. 1986. Affinity purification of sequence-specific DNA binding proteins. Proc. Natl. Acad. Sci. 83: 5889-5893.

Kadonaga, J.T., K.R. Carner, F. Masiarz, and R. Tiian. 1987. Isolation of cDNA encoding factor Spl and functional analysis of the DNA-binding domain. Cell 51: 1079-1090.

Klock, G., U. Strahle, and G. Schutz. 1987. Oestrogen and glu- cocorticoid responsive elements are closely related but distinct. Nature 329: 734-736.

Kozmik, Z., S. Wang, P. Dorfler, B. Adams, and M. Busslinger. 1992. The promoter of the CD19 gene is a target for the B-cell-specific transcription factor BSAP. Mol. Cell. Biol. 12: 2662-2672.

Kraulis, P.J., A.R.C. Raine, P.L. Gadhavi, and E.D. Laue. 1992. Structure of the DNA-binding domain of zinc GAL4. Nature 356: 448-450.

Kunkel, T.A. 1985. Rapid and site-specific mutagenesis without phenotypic selection. Proc. Natl. Acad. Sci. 82: 488-492.

Lees, J.A., S.E. Fawell, R. White, and M.G. Parker. 1990. A 22amino-acid peptide restores DNA-binding activity to dimerization-defective mutants of the estrogen receptor. Mol. Cell. Biol. 10: 5529-5531.

Lenardo, M.J. and D. Baltimore. 1989. NFкB: A pleiotropic activator of inducible and tissue-specific gene control. Cell 58: 227-229.

Marmorstein, R., M. Carey, M. Ptashne, and S.C. Harrison. 1992. DNA recognition by GAL4: structure of a proteinDNA complex. Nature 356: 408-414.

Martinez, E., F. Givel, and W. Wahli. 1987. The estrogen-responsive element as an inducible enhancer: DNA sequence requirements and conversion to a glucocorticoid-response element. $E M B O$ \%. 6: 3719-3727.

Matsuuchi, L., M.R. Gold, A. Travis, R. Grosschedl, A.L. DeFranco, and R.B. Kelly. 1992. The membrane IgM-associated proteins MB- 1 and Ig- $\beta$ are sufficient to promote surface expression of a partially functional B-cell antigen receptor in a nonlymphoid cell line. Proc. Nat1. Acad. Sci. 89: 3404-3408.

Matthias, P., M.M. Muller, E. Schreiber, S. Rusconi, and W. Schaffner. 1989. Eukaryotic expression vectors for the analysis of mutant proteins. Nucleic Acids Res. 17: 6418 .

Michelson, A.M., S.M. Abmayr, M. Bate, A. Martinez Arias, and T. Maniatis. 1990. Expression of a MyoD family member prefigures muscle pattern in Drosophila embryos. Genes \& Dev. 4: 2086-2097.

Miller, J., A.D. McLachlan, and A. Klug. 1985. Repetitive zincbinding domains in the protein transcription factor IIIA from Xenopus oocytes. EMBO J. 4: 1609-1614.

Müller, M.M., S. Ruppert, W. Schaffner, and P. Matthias. 1988. A cloned octamer transcription factor stimulates transcription from lymphoid-specific promoters in non- $\mathrm{B}$ cells. $\mathrm{Na}$ ture 336: 544-551.

Murre, C., P. Schonleber McCaw, and D. Baltimore. 1989. A new DNA binding and dimerization motif in immunoglobulin enhancer binding, daughterless, MyoD, and myc proteins. Cell 56: 777-783.

Reth, M. 1991. Signal transduction in B cells. Curr. Opin. Immunology 3: 340-344.

Rolink, A. and F. Melchers. 1991. Molecular and cellular origins of B lymphocyte diversity. Cell 66: 1081-1094.

Rudin, C., P.Engler, and U. Storb. 1990. Differential splicing of thymosin beta 4 mRNA. J. Immunol. 144: 4857-4862.

Sakaguchi, N., S.-I. Kashiwamura, M. Kimoto, P. Thalmann, and F. Melchers. 1988. B lymphocyte lineage-restricted expression of $m b-1$, a gene with CD3-like structural properties. EMBO J. 7: 3457-3464.

Sambrook, J., E.F. Fritsch, and T. Maniatis. 1989. Molecular cloning: A laboratory manual. Cold Spring Harbor Laboratory Press, Cold Spring Harbor, New York.

Sen, R. and D. Baltimore. 1986. Inducibility of $\kappa$ immunoglobulin enhancer-binding protein NF- $\mathrm{B}$ by a posttranslational mechanism. Cell 47: 921-928.

Staudt, L. and M.J. Lenardo. 1991. Immunoglobulin gene transcription. Annu. Rev. Immunol. 9: 373-398. 
Staudt, L.M., R.G. Clerc, H. Singh, J.H. Lebowitz, P.A. Sharp, and D. Baltimore. 1988. Cloning of a lymphoid-specific cDNA encoding a protein binding the regulatory octamer DNA motif. Science 241: 577-580.

Suzuki, T., M. Sato, T. Yoshida, and S. Tuboi. 1989. Rat liver mitochondrial and cytosolic fumarases with identical amino acid sequences are encoded from a single gene. J. Biol. Chem. 264: 2581-2586.

Travis, A., A. Amsterdam, C. Belanger, and R. Grosschedl. 1991a. LEF-1, a gene encoding a lymphoid-specific protein with an HMG domain, regulates T-cell receptor $\alpha$ enhancer function. Genes \& Dev. 5: 880-894.

Travis, A., J. Hagman, and R. Grosschedl. 1991b. Heterogeneously initiated transcription from the pre-B and B-cellspecific $m b-1$ promoter: Analysis of the requirement for upstream factor-binding sites and initiation site sequences. Mol. Cell. Biol. 11: 5756-5766.

Travis, A., J. Hagman, L. Hwang, and R. Grosschedl. 1993. Purification of early $B$ cell factor and characterization of its DNA-binding specificity. Mol. Cell. Biol. (in press).

Venkitaraman, A.R., G.T. Williams, M. Dariavach, and M. Neuberger. 1991. The B-cell antigen receptor of the five immunoglobulin classes. Nature 352: 777-781.

Vinson, C.R. and K.C. Garcia. 1992. Molecular model for DNA recognition by the family of basic helix-loop-helix zipper proteins. New Biol. 4: 396-403.

Voronova, A. and D. Baltimore. 1990. Mutations that disrupt DNA binding and dimer formation in E47 helix-loop-helix protein map to distinct domains. Proc. Natl. Acad. Sci. 87: 4722-4726.

Westin, G., T. Gerster, M.M. Muller, G. Schaffner, and W. Schaffner. 1987. OVEC, a versatile system to study transcription in mammalian cells and cell-free extracts. Nucleic Acids Res. 15: 6787-6797. 


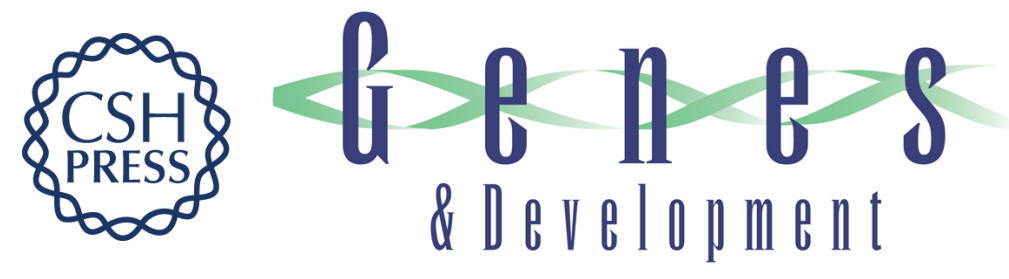

\section{Cloning and functional characterization of early B-cell factor, a regulator of lymphocyte-specific gene expression.}

J Hagman, C Belanger, A Travis, et al.

Genes Dev. 1993, 7:

Access the most recent version at doi:10.1101/gad.7.5.760

References This article cites 56 articles, 22 of which can be accessed free at:

http://genesdev.cshlp.org/content/7/5/760.full.html\#ref-list-1

License

Email Alerting

Service

Receive free email alerts when new articles cite this article - sign up in the box at the top right corner of the article or click here.

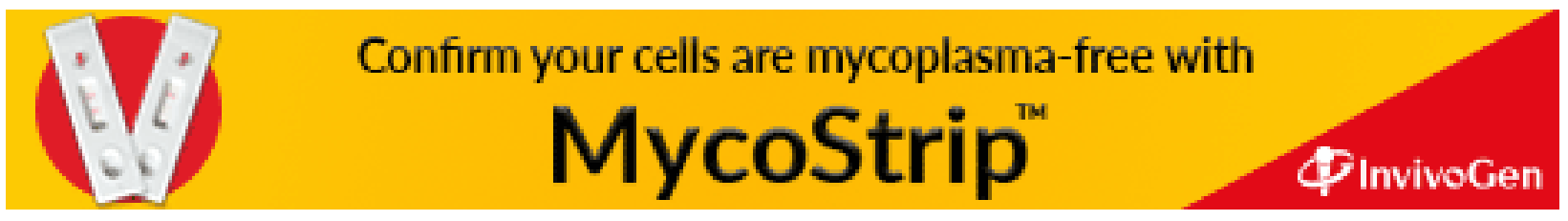

